\title{
IDETC2008-50027
}

\section{PLUG-IN HYBRID VEHICLE SIMULATION: HOW BATTERY WEIGHT AND CHARGING PATTERNS IMPACT COST, FUEL CONSUMPTION, AND $\mathrm{CO}_{2}$ EMISSIONS}

\author{
Richard Hauffe \\ Research Assistant \\ Mechanical Engineering \\ Carnegie Mellon University
}

\author{
Constantine Samaras \\ Research Assistant \\ Engineering and Public Policy \\ Civil and Environmental Engineering \\ Carnegie Mellon University
}

\author{
Jeremy J. Michalek \\ Assistant Professor \\ Mechanical Engineering \\ Engineering and Public Policy \\ Carnegie Mellon University
}

\begin{abstract}
Plug-in hybrid electric vehicle (PHEV) technology is receiving attention as an approach to reducing U.S. dependency on foreign oil and emissions of greenhouse gases (GHG) from the transportation sector. Because plug-in vehicles require large batteries for energy storage, battery weight can have a significant impact on vehicle performance: Additional storage capacity increases the range that a PHEV can travel on electricity from the grid; however, the associated increased weight causes reduced efficiency in transforming electricity and gasoline into miles driven.

We examine vehicle simulation models for PHEVs and identify trends in fuel consumption, operating costs, and GHG emissions as battery capacity is increased. We find that PHEVs with large battery capacity consume less gasoline than small capacity PHEVs when charged every 200 miles or less. When charged frequently, small capacity PHEVs are less expensive to operate and release fewer GHGs, but medium and large capacity PHEVs are more efficient for drivers that charge every 25-100 miles. While statistics on average commute length suggest that frequent charges are possible, answering the question of which PHEV designs will best help to achieve national goals will require a realistic understanding of likely consumer driving and charging behavior as well as future trends in electricity generation.
\end{abstract}

\section{INTRODUCTION}

Increasing concerns regarding high oil prices, oil dependency, and climate change have resulted in policymakers and the automobile industry evaluating alternative strategies for passenger transportation. PHEV technology offers a possible approach to reducing U.S. dependency on foreign oil and GHG emissions via the use of large rechargeable storage batteries to enable electricity to provide a portion of the propulsion requirements of a passenger vehicle. Since approximately $60 \%$ of U.S. passenger vehicle miles are traveled by vehicles driving less than 30 miles per day (USDOT 2004), PHEVs may be able to displace a large portion of gasoline consumption with electricity. Additionally, the price differential between retail electricity and gasoline could make electric-powered travel more cost effective than gasoline, depending on the additional vehicle capital costs (Scott et al. 2006). However, the reduced fuel use, economic costs, and GHG emissions of PHEVs depend on the vehicle and battery characteristics, as well as source of electricity used for recharging. For example, the full life cycle GHG emissions associated with manufacturing and operating a PHEV are comparable to traditional hybrids under the current U.S. mix of electricity generation (Samaras and Meisterling 2008). Trends in electricity generation, battery manufacturing, and the use of biofuels have critical implications on the relative advantages of PHEVs.

There are several variants of PHEV design, and Bradley and Frank (2007) provide a review of the potential PHEV vehicle architectures. All PHEVs have a drivetrain that incorporates an electric motor and an internal combustion engine (ICE), both of which provide torque for vehicle propulsion (Bradley and Frank 2007). The storage battery of a PHEV, which can be recharged using conventional electrical outlets, would allow the vehicle to drive for a limited range solely (or primarily, depending on the configuration) via energy from the electricity grid. PHEV drivetrains could be arranged in parallel or in series. In a parallel configuration, generally both the electric motor and ICE provide power to the drivetrain after the storage battery has been depleted to approximately $20 \%$ of its initial state-of-charge (SOC). A parallel PHEV with a 20\% SOC would perform similarly to a traditional Toyota Prius hybrid (HEV). In a series configuration, the electric motor provides power to the drivetrain, with the ICE responsible for battery energy management. Series designs have been estimated to have lower fuel economy, lower efficiency, and higher component costs (Bradley and Frank 2007) and hence, we focus on parallel PHEVs.

Since PHEVs rely on large storage batteries for any economic or environmental benefits relative to traditional 
hybrids and ICE vehicles, the characteristics and design issues associated with PHEV batteries play an important role in the potential adoption of PHEVs. Consumer acceptance will depend on battery cost, operating cost, power and performance characteristics, battery cycle and calendar life, and safety, among other characteristics. The two dominant battery technologies considered likely candidates for PHEVs are nickel-metal hydride (NiMH) and lithium-ion (Li-ion) batteries. $\mathrm{NiMH}$ batteries have performed well in existing hybrids and electric vehicles (EPRI 2004), but their relatively low energy density implies large, heavy batteries for extended electric travel. Li-ion batteries have higher energy densities and are benefiting from increased technological advancement, but concerns regarding calendar life, safety (internal corrosion could cause Li-ion batteries to burst into flames), and lack of widespread testing in vehicles remain (Karden et al. 2007). We focus here on NiMH batteries due to model availability, and we leave $\mathrm{Li}$-ion studies for future work.

NiMH batteries with an approximate mass of $100-260 \mathrm{~kg}$ could enable a range of up to $\sim 60$ miles in electric vehicle (EV) mode. The energy required to produce the raw materials and manufacture the NiMH battery account for approximately 3$10 \%$ of the life cycle energy and GHG impacts from PHEVs (Samaras and Meisterling 2008). Additionally, battery mass in PHEVs is sufficient enough to affect fuel economy and acceleration during vehicle operations. Due to data constraints, previous studies evaluating the GHG benefits of PHEVs assumed that the additional weight of potentially large storage batteries did not affect the gasoline fuel economy or the electrical requirements for propulsion (Kintner-Meyer, Schneider et al. 2006; EPRI 2007; Samaras and Meisterling 2008). However, a preliminary estimation of the impact of weight and power on traditional hybrids found that weight decreases hybrid fuel economy (Reynolds and Kandlikar 2007). To examine in detail design tradeoffs between battery capacity and PHEV benefits, we use the vehicle physics simulator ADVISOR (Markel et al. 2002; AVL 2004) to model the effects of increased battery weight on fuel economy, cost, and GHG emissions for PHEVs.

\section{EFFECTS OF LARGE BATTERIES ON PHEV PERFORMANCE}

Conventional vehicles that hold more fuel can travel farther without refueling. Similarly, PHEVs with larger battery capacity can travel farther on electricity before drawing on liquid fuel. However, batteries have a considerably lower energy density than liquid fuel: When a vehicle is filled with 10 gallons of gasoline, the vehicle weighs an additional $80 \mathrm{lbs}$, and it gradually loses those $80 \mathrm{lbs}$ of weight as the fuel is burned in the engine. A PHEV battery may weigh $400 \mathrm{lbs}$, and the vehicle must carry this weight even after the battery is depleted. Additional battery weight decreases the attainable efficiency in miles per $\mathrm{kWh}$ in EV mode as well as miles per gallon in hybrid-mode (i.e.: once the battery is depleted to its lower target SOC). Thus, while increased battery capacity increases
EV range, it decreases efficiency both in electric and in hybrid mode.

Because extra weight requires additional structural support in the vehicle body and chassis, we account for the structural weight required to support each additional pound of battery. Via informal discussions with automakers, we estimate that 0-2 pounds of structural weight is required per pound of battery. Additional structural weight requirements depend on the type of vehicle: If the vehicle structure is optimized for light weight, then adding the additional weight of batteries will require additional structural weight; however, if the vehicle is weightconstrained by other considerations, such as crash-test performance or hauling capacity, then the vehicle may not require additional structural weight to carry the batteries. We treat the case of one pound of structural weight per pound of battery as the base case and examine $0-2$ pounds in a sensitivity analysis. Finally, we also account for the weight of larger electric motors required to maintain target 0-60 miles per hour (mph) acceleration times for heavier vehicles.

\section{PLUG-IN VEHICLE SIMULATION}

Vehicle simulations were performed using AVL's ADVISOR program, originally developed by the National Renewable Energy Laboratory and the Partnership for a New Generation of Vehicles and later transferred to AVL (Markel et al. 2002; AVL 2004). ADVISOR is a backward-facing vehicle simulator, meaning it takes as input a profile of desired speeds at every time step and determines what engine and motor performance characteristics are needed at each time step to achieve the specified profile. Thus, the flow of information is from tire to axle to gearbox, and so on, in contrast to forwardfacing vehicle simulators, which model the driver as a control system that responds to the observed vs. desired vehicle speed using accelerator and brake pedals.

We simulated a parallel hybrid configuration starting in EV mode, such that the car can drive on battery power alone without engaging the gasoline engine until the battery reaches a low SOC. For all simulations, the vehicle was initiated with a full $100 \%$ SOC and was depleted in EV mode until 20\% SOC, at which point the gasoline engine engaged and the car began running in hybrid mode (i.e.: as a traditional HEV). In this way, we examine the effect of the distance traveled between charges by observing how average performance characteristics change as the distance increases, assuming that each charge at an electrical outlet brings the battery back to a $100 \%$ SOC.

The design variables controlled in this simulation were the number of battery modules and the size (power scaling factor) of the electric motor and gasoline engine. All vehicle cases used the same base configuration: The engine model is based on a 1991 Geo Metro SI41, a relatively weak engine with $41 \mathrm{~kW}$ maximum power at $5,700 \mathrm{rpm}$ and a peak torque of $81 \mathrm{Nm}$ at $3,477 \mathrm{rpm}^{1}$. The engine map is based on measured dynamometer data that is scaled up or down to predict

\footnotetext{
${ }^{1}$ ADVISOR model FC_SI41_emis.m
} 
performance and weight of larger or smaller power engines. The vehicle body load parameters are based on the 1994 Saturn SL1 vehicle, with a drag coefficient of 0.335 , a frontal area of 2 $\mathrm{m}^{2}$ and a mass (without any propulsion system) of $592 \mathrm{~kg}$, including $136 \mathrm{~kg}$ of cargo mass ${ }^{2}$. The 1994 Saturn SL1 has 0.34 cubic meters of trunk space and 2.5 cubic meters of passenger space ${ }^{3}$. The transmission is a four speed automatic, and default gear change control parameters were used. The motor is based on a Westinghouse $75 \mathrm{~kW} \mathrm{AC}$ induction motor ${ }^{4}$ and was scaled similarly to the engine to predict performance and weight of larger or smaller engines. The battery model is based on an Ovonic NiMH battery with each module having $8.4 \mathrm{~kg}$ weight, 3.4 cubic cm volume, $0.6 \mathrm{kWh}$ nominal energy, $12 \mathrm{~V}$ nominal voltage, and $45 \mathrm{Ah}$ nominal capacity ${ }^{5}$. The total battery size and capacity was scaled up or down by specifying an integer number of battery modules. Additional structural weight in the body and chassis required to support the weight of the battery was accounted for as a factor of the battery's weight, ranging from $0 \mathrm{x}, 1 \mathrm{x}$ and $2 \mathrm{x}$ component weight. Structural weight required to support larger electric motors was ignored.

The simulated driving cycle specified to measure fuel efficiency is the Federal Test Procedure (FTP) driving cycle used by the EPA for emissions certification of passenger vehicles, as seen in Figure 1. The course is 11 miles long and lasts about 41 minutes, including 22 stops and a max speed of $56.7 \mathrm{mph}$.

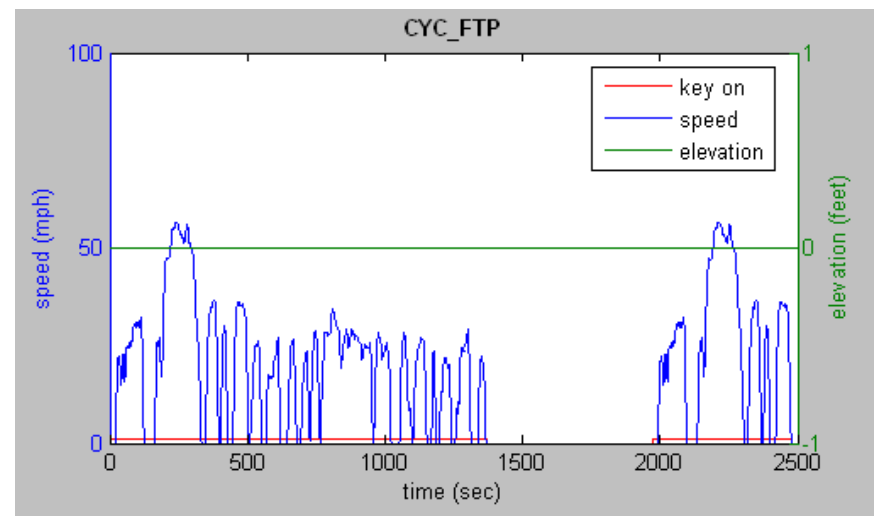

Figure 1: FTP driving cycle used in all simulations

Hybrid vehicles have been generally classified as full or mild hybrids, depending on the role that the engine plays (Burke 2007). An HEV is considered a full hybrid when the engine has been scaled down and the electric motor is relatively large in order to support EV driving modes. An HEV is considered a mild hybrid if the motor is relatively small, acting to provide additional torque for moments of acceleration. The ability of full hybrids to operate in EV mode is advantageous

\footnotetext{
${ }^{2}$ ADVISOR model VEH_SMCAR.m

${ }^{3}$ Source: http://www.fueleconomy.gov/feg/noframes/10965.shtml

${ }^{4}$ ADVISOR model MC_AC75.m

${ }^{5}$ ADVISOR model ESS_NIMH45_OVONIC.m
}

for PHEVs because of the ability to obtain cheaper energy from the electricity grid. Additionally, the electric-only drive mode of PHEVs could facilitate operations in a city center that has limited the use of ICEs (Bradley and Frank 2007). We restrict attention to full hybrids so that electric-only travel is possible using electricity from the grid (Karden et al. 2007). For simulation, control strategy parameters were set so that the vehicle operates in EV mode until the battery reaches a $20 \%$ SOC, after which time the vehicle switches to hybrid mode. During EV mode, the engine is not engaged, even if operating conditions call for high torque. Instead, the motor was scaled in order to achieve target $0-60 \mathrm{mph}$ acceleration times without engine assistance.

\section{Vehicle Performance}

Simulations were performed to test 20,40, and 60-mile EV range PHEVs under assumptions of $0 \mathrm{x}, 1 \mathrm{x}$, and $2 \mathrm{x}$ structural weight per additional pound of battery, motor and engine. For each case, the number of battery modules needed to reach the target EV range was determined. Motor size (power) was then adjusted to achieve a $0-60 \mathrm{mph}$ acceleration time of 10 seconds ${ }^{6}$ in EV mode, which is approximately the acceleration performance of a Toyota Prius. Finally, the engine power was adjusted if necessary to ensure the same performance in hybrid mode. This procedure was repeated iteratively until convergence to a vehicle profile that satisfied target range and acceleration for each case, accounting for weight.

Cost calculations are based on $\$ 0.10$ per $\mathrm{kWh}$ of electricity and $\$ 3.00$ per gallon of gasoline. Emissions calculations assume $0.670 \mathrm{~kg}$ of $\mathrm{CO}_{2}$ emitted per $\mathrm{kWh}$ of electricity and $11.34 \mathrm{~kg}$ of $\mathrm{CO}_{2}$ per gallon (gal) of gasoline. These values represents the average life cycle emissions, including combustion and the upstream fuel cycle (Samaras and Meisterling 2008). For gasoline, $8.81 \mathrm{~kg} \mathrm{CO}_{2} /$ gal is generated in combustion and $2.54 \mathrm{~kg} /$ gal of $\mathrm{CO}_{2}$ is emitted in the supply chain (Wang 2001; EPA 2006). The $\mathrm{CO}_{2}$ emissions associated with manufacturing the vehicle and the battery were not considered. The total operating cost to travel $x$ miles between charges is the sum of the cost of the electricity needed to charge the battery and the cost of the gasoline used. For distances less than the EV range, the battery was only charged as much as needed for the trip. For distances greater than the EV range, the battery was fully charged.

\section{RESULTS}

Table 1 summarizes the simulation results, which reveal that additional weight affects EV range, EV efficiency, (gasoline) fuel efficiency, operating cost, and GHG emissions. Greater motor power is needed to achieve baseline acceleration performance as the vehicle weight increases, although the weight of the larger motor itself is small compared to the additional battery weight. Increased weight also requires more

\footnotetext{
${ }^{6}$ Due to the discrete nature of the battery modules, the target range was not achieved precisely, but all results are within $4 \%$ of the target.
} 
batteries to achieve a target $\mathrm{EV}$ range, which compounds the effect because the additional batteries contribute additional weight. We will examine the effect of $\mathrm{EV}$ range for equivalentacceleration-performance vehicles on fuel economy, operating cost, and GHG emissions in the following sections. Table 1 shows each of these metrics for three different values of distance traveled between charges: 50, 100, and 150 miles, and the preferred PHEV range is highlighted for each case.

\section{Fuel Economy:}

The results of hybrid fuel economy in Table 1 show that as the target EV range increases from 20 miles to 60 miles, hybrid mode fuel efficiency decreases from 40.0 miles per gallon (mpg) to $30.8 \mathrm{mpg}$ in the $1 \mathrm{x}$ base case due to increased weight. Larger capacity PHEVs can travel longer without burning gasoline, but they burn more gasoline per mile once the battery is drained. This effect is reduced under lower structural weight assumptions and amplified for larger structural weight.

Figure 2 shows the average fuel consumption per mile for each case as a function of the distance traveled between charges. Below the EV range in each case, the vehicle consumes no gasoline. Beyond the EV range, fuel is consumed at a greater rate for the heavier vehicles. The graph shows that larger capacity PHEVs consume less gasoline as long as the vehicle is charged every 200 miles or less ( 150 miles in the $2 \mathrm{x}$ case and $>300$ miles in the $0 x$ case). Given such long distances, it is clear that larger capacity PHEVs will reduce gasoline consumption in most likely use conditions. Figure 3 shows this data for total gallons consumed.

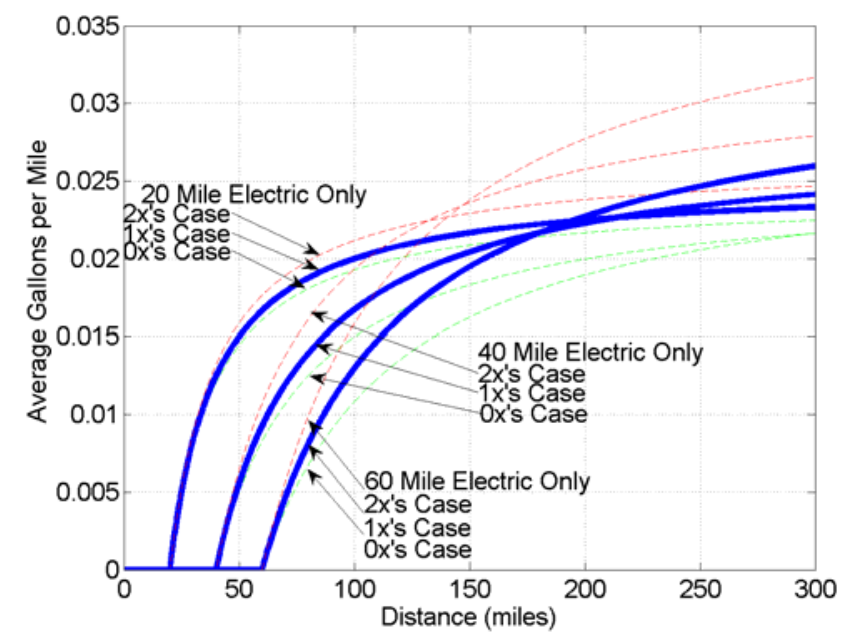

Figure 2: Average fuel consumption per mile

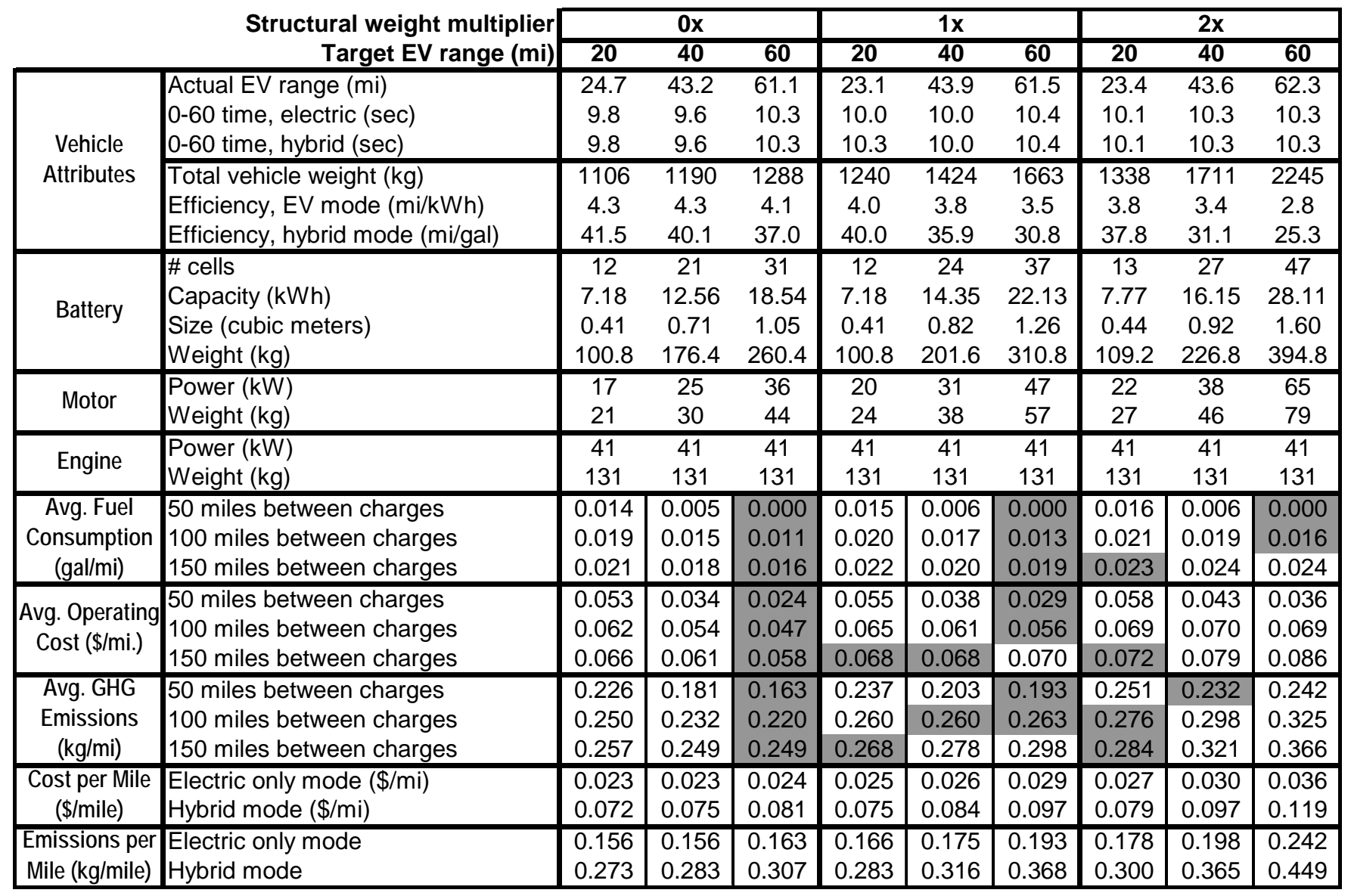

Table 1 Summary of simulation results 


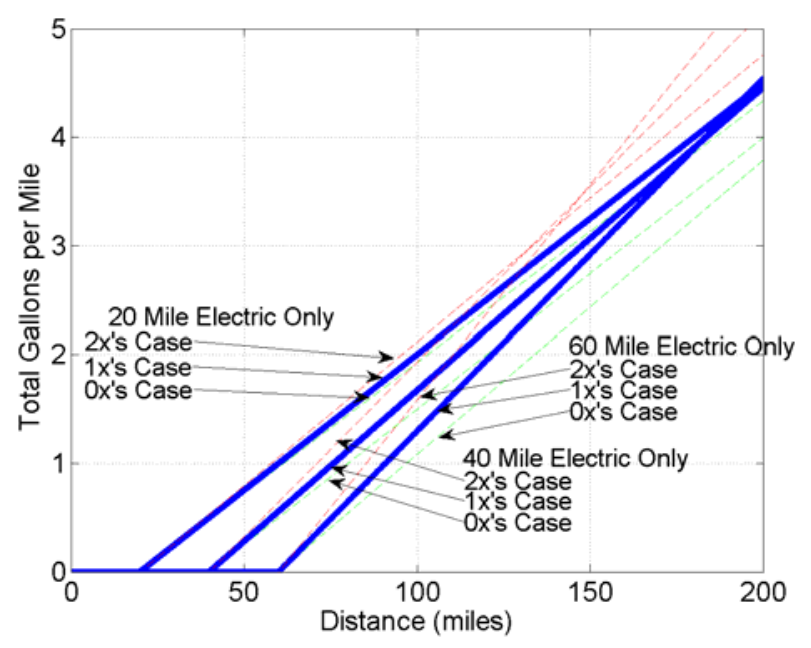

Figure 3: Cumulative fuel consumption

\section{Cost}

Cost was calculated as the price of the energy (electricity or gasoline) required to drive one mile. The cost of gasoline continues to rise nationally, and the cost of electricity is somewhat less volatile. Table 1 shows the cost per mile for electric-only mode and hybrid mode for each case, assuming $\$ 0.10$ per $\mathrm{kWh}$ and $\$ 3$ per gallon. Larger capacity PHEVs are heavier, thus increasing the operation cost in both $\mathrm{EV}$ and hybrid mode; however, they also extend the distance that the vehicle operates in the less-expensive EV mode.

Figure 4 shows the average cost per mile as a function of distance between charges. For frequent charges, a PHEV with an EV range approximately equal to the distance between charges minimizes cost. For moderate distances traveled between charges, between about 25 and 100 miles, larger capacity PHEVs are less expensive per mile. For long distances between charges, over 150 miles, small capacity PHEVs become less expensive once again. Figure 5 shows cumulative cost.

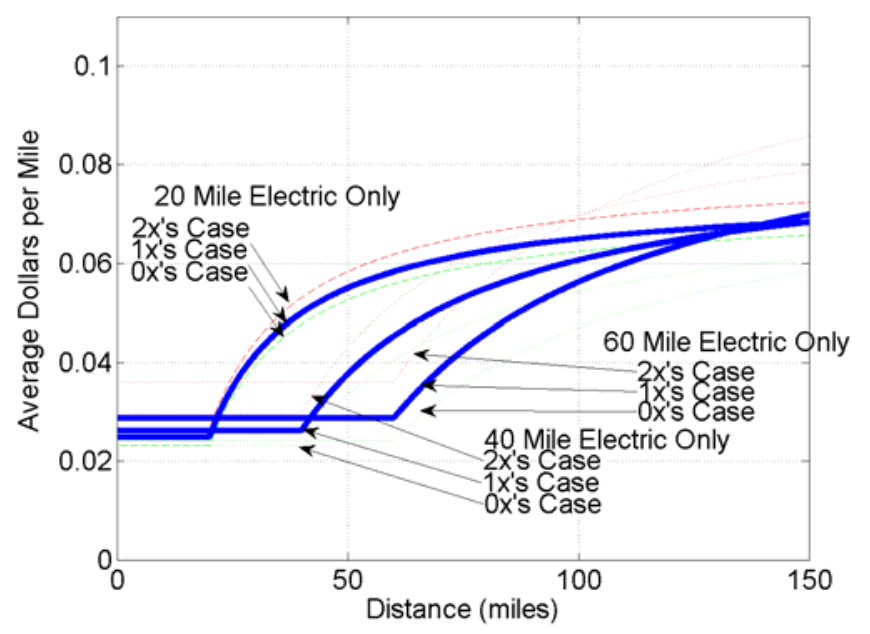

Figure 4: Average operating cost per mile

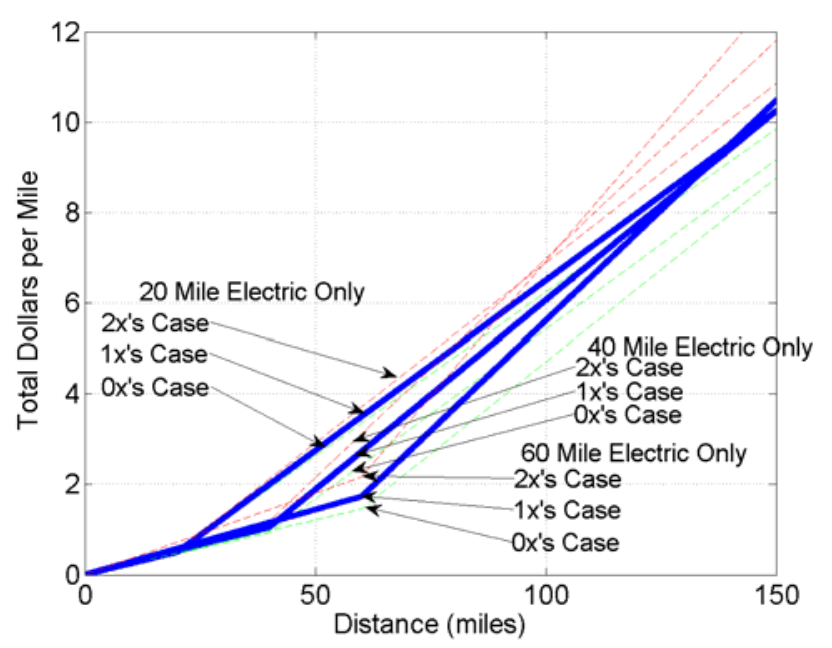

Figure 5: Cumulative operating cost

\section{GHG Emissions:}

Greenhouse gas emissions were calculated separately for each energy source to include combustion and supply chain emissions associated with operation, as described previously. Table 1 lists the amount of GHGs emitted per mile for each case in both EV mode and hybrid mode. The data shows that gasoline emits roughly 1.5-2 times as much GHGs as electricity per mile. Figure 6 shows average GHG emissions $\left(\mathrm{CO}_{2}\right.$ equivalent) per mile as a function of distance traveled between charges. For frequent charging, a small capacity PHEV (sized to the average distance between charges) reduces emissions. For moderate distances of about 25 to 100 miles, larger capacity PHEVs reduce emissions. Finally, for distances above $\sim 100$ miles (70 miles for the $2 \mathrm{x}$ case and $>150$ miles for the $0 \mathrm{x}$ case), small PHEVs release fewer GHGs per mile. Figure 7 shows cumulative GHG emissions.

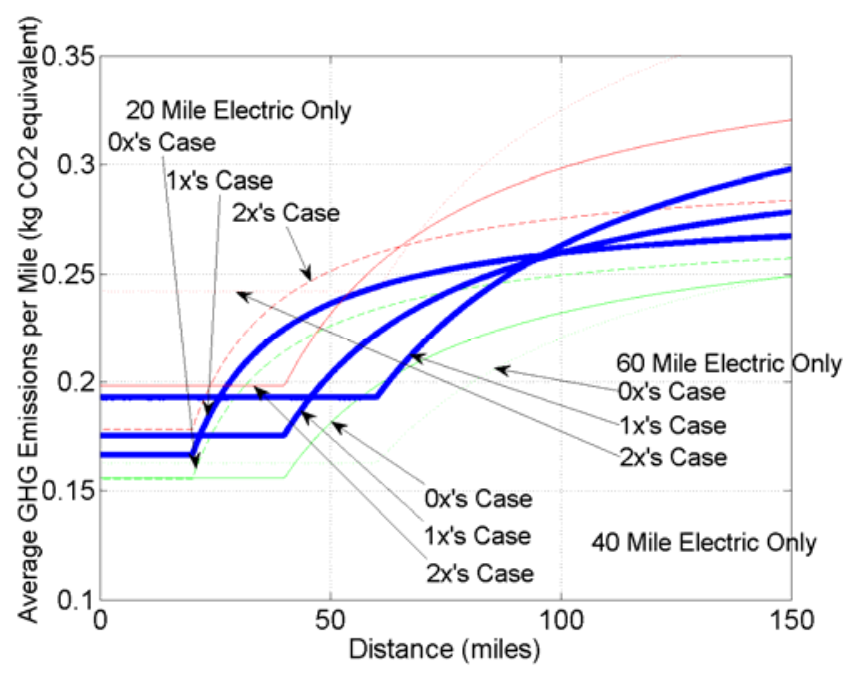

Figure 6: Average GHG emissions per mile 


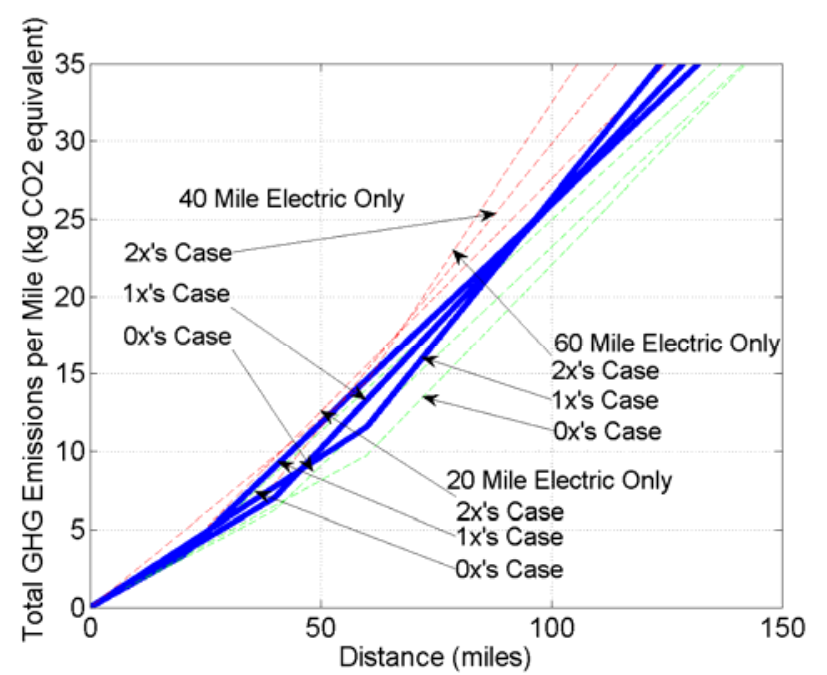

Figure 7: Cumulative GHG emissions

\section{CONCLUSIONS}

Our simulation results indicate that battery weight is a key factor affecting the cost, emissions, and fuel economy of PHEVs. The best choice of PHEV battery capacity depends on the distance that the vehicle will be driven between charges as well as the structural weight required to carry the batteries. Because $60 \%$ of U.S. passenger vehicle miles are traveled by vehicles driving less than 30 miles per day, there exists potential to reduce cost and GHG emissions by sizing battery capacity appropriately. Thirty miles per day suggests that the ideal capacity should achieve a 30 mile range; however, there are three potential complications: 1) if the variance in miles traveled per day is large, then a capacity designed for the average distance may be suboptimal; 2) it is unclear whether it is safe to assume that drivers will charge their vehicles every night - irregular charging behavior could lead to significantly longer distances between charges than the average daily distances would suggest; and conversely, 3) widespread installation of charging infrastructure in public parking places would enable charging more than once per day, enabling shorter distances between charges.

These results lead us to make several recommendations: First, ignoring the effect of battery weight on vehicle efficiency may overestimate the benefits of PHEVs, particularly for heavy $\mathrm{NiMH}$ batteries and cases that require substantial structural weight. This effect calls for greater attention in PHEV studies. Battery weight can lower a vehicle's fuel economy by as much as $40 \%$ when operating in hybrid mode. While the importance of hybrid-mode fuel efficiency is mitigated for frequent charges, it dominates when vehicles are driven longer distances between charges. Secondly, further research is needed to determine appropriate estimates for the distribution of miles that PHEV drivers will travel between vehicle charges. Infrastructure advancements, such as automatic charging connections installed in garages or designated public parking spaces, may help to ensure frequent charging; however, in the near-term it may be unrealistic to assume that consumers will charge their vehicles every night, despite the economic benefit. Because economic, environmental, and fuel consumption implications of PHEVs are sensitive to this variable, research to better understand and predict driver behavior is warranted.

Lighter batteries would mitigate some of the loss in energy economy associated with increased EV range. In future work we intend to examine Li-ion batteries, which have higher energy densities than NiMH batteries. Table 1 shows that the expected NiMH battery size for PHEVs in the study lies between 0.4 and $1.6 \mathrm{~m}^{3}$. Since the Saturn vehicle body used in the study has trunk space of only $0.34 \mathrm{~m}^{3}$, packaging is an important issue with PHEVs, and the larger capacity vehicles require excessive sacrifice of passenger and cargo capacity. Additionally, we have accounted only for cost and GHG emissions associated with the use phase of vehicles. Because PHEVs are more expensive to purchase and require more energy to produce, vehicle production and purchase should be included in order to paint a more complete picture of tradeoffs. A life cycle comparison of capital and operating costs between $\mathrm{NiMH}$ and Li-ion technology in PHEVs with different EV ranges is an interesting topic for future research. Finally, the role of government incentives and consumer preferences in bringing PHEV technology to market will have a substantial impact on PHEV capacity chosen by automakers (Michalek et al. 2004). Battery cost is currently very high, and government incentives may make the difference as to whether or not early PHEVs will be adopted at a significant scale. Examining the relative importance to consumers of attributes such as purchase cost, operating cost, and acceleration will shed greater light on which vehicles may emerge as successful in the competitive marketplace.

\section{ACKNOWLEDGMENTS}

This research was supported in part by 1) the Climate Decision Making Center, which has been created through a cooperative agreement between the National Science Foundation (SES-0345798) and Carnegie Mellon University; 2) by a grant from the National Science Foundation program for Material Use, Science, Engineering and Society: Award \#0628084, and 3) by a grant from Ford Motor Company.

\section{REFERENCES}

USDOT (2004) "2001 National Household Travel Survey", U.S. Department of Transportation.

EPRI (2004) "Advanced Batteries for Electric Drive Vehicles", Palo Alto, EPRI TR1009299.

EPRI (2007). Environmental assessment of plug-in hybrid electric vehicles, Volume 1: Nationwide greenhouse gas emissions. Palo Alto, EPRI, Palo Alto, CA.

EPA (2006) "Inventory of U.S. Greenhouse Gas Emissions and Sinks: 1990-2004", Washington, D.C., U.S. Environmental Protection Agency. 
AVL (2004) ADVISOR 2004 User' Guide, Plymouth, Michigan, AVL North America, Inc.

Bradley, T. H. and A. A. Frank (2007) "Design, demonstrations and sustainability impact assessments for plug-in hybrid electric vehicles," Renew Sustain Energy Rev: doi: 10.1016/j.rser.2007.05.003.

Burke, A. F. (2007) "Batteries and ultracapacitors for electric, hybrid, and fuel cell vehicles," Proceedings of the IEEE, 95(4): 806-820.

Karden, E., S. Ploumen, B. Fricke, T. Miller and K. Snyder (2007) "Energy storage devices for future hybrid electric vehicles," Journal of Power Sources, 168(1): 2-11.

Kintner-Meyer, M., K. Schneider, and R. Pratt (2006). Impacts assessment of plug-in hybrid vehicles on electric utilities and regional U.S. power grids, Part 1: Technical analysis, Pacific Northwest National Laboratory.

Markel, T., A. Brooker, I. Hendricks, V. Johnson, K. Kelly, B. Kramer, M. O'Keefe, S. Sprik and K. Wipke (2002) "ADVISOR: a systems analysis tool for advanced vehicle modeling," Journal of Power Sources, 110(2): 255-266.
Michalek, J. J., P. Y. Papalambros and S. J. Skerlos (2004) "A study of fuel efficiency and emission policy impact on optimal vehicle design decisions," ASME Journal of Mechanical Design, 126(6): 1062-1070.

Reynolds, C. and M. Kandlikar (2007) "How hybrid-electric vehicles are different from conventional vehicles: the effect of weight and power on fuel consumption," Environmental Research Letters, 2: 014003.

Samaras, C. and K. Meisterling (2008) "Life cycle assessment of greenhouse gas emissions from plug-in hybrid vehicles: Implications for policy," Environ. Sci. Technol., In-press.

Scott, M. J., M. Kintner-Meyer, D. Elliot, B. and W. M. Warwick (2006) "Impacts assessment of plug-in hybrid vehicles on electric utilities and regional U.S. power grids, Part 2: Economic Assessment", Pacific Northwest National Laboratory.

Wang, M. (2001) "Development and use of GREET 1.6 fuelcycle model for transportation fuels and vehicle technologies", Argonne National Laboratory, Argonne, IL. 